\title{
Efficacy of Platelet-Rich Plasma for Arthroscopic Treatment of Chronic Shoulder Impingement Syndrome: A Retrospective Study with a Minimum of 3 Years of Follow-Up
}

Keywords: Acromioplasty; Platelet-rich plasma; Arthroscopic; Impingement synd rome

\begin{abstract}
Aim: This study a imed to determine whether PRP in adjunction of arthrosc opic acromioplasty waseffec tive forrotatorc uff tend inopathie (RCT).

Materials and Methods: Patients (age range, 23 to 73 years) were considered for enrollment if they had shoulder impingement synd rome and 6 months of active conservative treatment had failed, positive radiographic evidence of type II or III acromion, and magnetic resonance imaging or ultrasound evidence of RCT. Patients $(N=53)$ underwent consecutive arthroscopic acromioplasty between 2008 and 2012. One group had arthroscopic subacromial decompression with an injection of PRP $(\mathrm{N}=24)$ and the other one simple arthrosc opic subacromial decompression $(\mathrm{N}=29)$. Outcomes evaluation consisted of self-reported pain via a visual analog scale, as well as functional assessment (Constant sc ore, and quick DASH questionnaire). Statistic al analyses were performed by use of factorial dependent-measures analysis of variance tests.
\end{abstract}

Results: Mean follow-up at the time of pain evaluation was 37,3 months $( \pm 9,1)$ for PRP group and 41,4 months $( \pm 10,2)$ for control group There was a significant difference for the two group between pre and post operative for pain scale. There was statistical difference of the last follow-up between the two groups for the pain evaluated by VAS The mean VAS at last follow-up was $1,17( \pm 1,27)$ for PRP vs $2,5( \pm 1,69)$ for control group $(p=0,002)$ respectively. Even there was a significant difference for the two group between pre and postoperative for functional score. There was no statistical difference at the last followup between the two groups.

Conclusions: The results suggest that PRP optimize the pain relief of the subacromial decompression in SIS. Level of Evidence: Level IV, retrospective study.

\section{Introduction}

Rotator cuff tendinopathie (RCT), also referred to as "shoulder impingement syndrome (SIS)", is the most common pathology encountered in the shoulder [1]. RCT causes pain and limits patients' movements, thereby preventing activities of daily living and often resulting in time away from work [2]. The prevalence of shoulder conditions increases with age over 50 years. RCT is believed to originate from extrinsic causes, intrinsic causes, or a combination of both. Extrinsic causes, which result in compression of the rotator cuff tendons and surrounding tissues, include anatomical
Journal of

Orthopedics \& Rheumatology

\section{Zbili David*, Brunet Thibault, Amsallem Lior and Serane J ulien \\ Doctor, Department of Orthopedics, Bichat Hospital, Paris}

*Address for Correspondence

Zbili David, Doctor, Department of Orthopedics, Bichat Hospital, 46 Rue Henrie Huchard 75018, Paris, E-mail: zbilidavid@gmail.com

Submission: 14 November, 2016

Accepted: 20 December, 2016

Published: 28 December, 2016

Copyright: () 2016 David Z, et al. This is an open access article distributed under the Creative Commons Attribution License, which permits unrestricted use, distribution, and reproduction in any medium, provided the original work is properly cited.

variants of the acromion, a thickened coracoacromial ligament, subacromial bursitis, or postural abnormalities [3,4]. Intrinsic causes are associated with degeneration of the rotator cuff tendons and include age-related degeneration that may vary in severity according to genetic predisposition, a deficient vascular supply, a history of intensive work [5] or tobacco [6]. The diagnosis of SIS is usually based on the patient's history and on clinical exam such as the impingement tests. The first line of treatment for RCT is conservative management, which may involve any combination of the following: antiinflammatory medications, corticosteroid injections, or exercises. Surgery is indicated in patients in whom conservative treatment has failed and multiple surgical techniques exist. Acromioplasty, also referred to as "subacromial decompression", is a surgical technique described by Neer in 1972, and it is routinely used in the treatment of RCT today [3]. Over the time, surgical techniques have evolved from open procedures to arthroscopic, which avoid wide dissection and subsequent large scarring. Some authors claim that arthroscopic procedures allow for quicker operating times, better post-operative mobility, and less complications, whereas others believe that the two procedures are equivalent in terms of efficacy and quality of life.

The use of platelet-rich plasma (PRP) as a modern and attractive solution to improve rotator cuff tendon healing has gained popularity over the last several years. PRP, most simply defined as a sample of autologous blood with great concentrations of platelets, can be applied by direct injection to repaired tissues [7]. Early clinical evidence suggests that PRP improves pain and function outcomes in some tendinopathies compared to control injection [8] and baseline status [9]. This could be explained by the analgesic effect of the PRP via the Protease-activated receptors 4 (PAR4) peptides [10]. Although there is variability among different commercially available products, the $\beta 1$, platelet min growth factors in PRP are transforming growth factor -derived growth factor, vascular endothelial growth factor, hepatocyte growth factor, and insulin-like growth factor 1 . These autologous growth factors may play a role in regeneration of tendon tissue through increased tendon cell proliferation, collagen synthesis, and vascularization. At present, there are ample in vitro and animal studies that have shown the positive effect of PRP on tendon collagen deposition and tendon vascularization. 
Citation: David Z, Thibault B, Lior A, Julien S. Efficacy of Platelet-Rich Plasma for Arthroscopic Treatment of Chronic Shoulder Impingement Syndrome: A Retrospective Study with a Minimum of 3 Years of Follow-Up. J Orthopedics Rheumatol. 2016; 3(2): 5.

The goal of this study was to know if adjunction of PRP on an arthroscopic acromioplasty procedure might improve improves pain and function outcomes in some RCT who resisting to the conservative management.

\section{Methods}

A consecutive series of patients who underwent arthroscopic acromioplasty between 2008 and 2012 in Bichat Claude-Bernard hospital, were enrolled in the present comparative study.

The inclusion criteria were symptomatic patients with a SIS resisting to the conservative treatment with no transfixing RC tears confirmed by the IRM. Patients were excluded if they had transfixing rotator cuff tear, acromio-clavicular osteoarthritis, a history of shoulder surgery, and calcification of the RC. 53 patients met the inclusion criteria. The patients were separated in two groups and operated by the same surgeon: a group PRP of 24 patients were injected in the tendon with PRP in addition to the arthroscopic acromioplasty and a group control of 29 patients who underwent simple arthroscopic acromioplasty without injection of PRP. The two groups were similar in terms of epidemiologic and per operative data (Table 1). One patient of control group was lost. All patients of the study had a loyal explanation.

\section{Surgical procedure}

All the patients underwent the same surgical procedure with the same surgeon. All procedures were performed on patients in the beach-chair position under general anesthesia. A posterior portal was first established for initial assessment of the scapulohumeral joint, with completion during the procedure via 2 additional portals. During examination, osteoarthritis of scapulo-humeral joint, superficial RC tears and associated biceps tendon lesions were inspected carefully. Biceps' tenotomy was undertaken in case of lesion and simple debridement of a superficial RC tears in case of no transfixing RC lesions. The arthroscope was then moved from inside the shoulder joint to the subacromial space. Here the bursitis and area of impingement was viewed directly. The inflamed bursa was removed using an electro-cautery device that vaporizes the tissue. A 5 $\mathrm{mm}$ high-speed bur was then used to remove some bone from undersurface of the acromion to prevent impingement.

In PRP group, at the end of the procedure, the patients were injected with ACP. The autologous platelet-rich plasma was prepared with the ACP $\odot$ Arthrex system with no adjuvant. Two syringes (10 $\mathrm{ml}$ ) of peripheral venous blood were taken (usually at the ankle) at the end of the intervention. The blood sample was centrifuged for 5 minutes at 1500 revolutions per minute and the supernatant was collected for the surgical injection (Figure 1). The injection was performed immediately after centrifugation for maximal efficiency. $10 \mathrm{cc}$ syringes with a 21 gauge, $4 \mathrm{~mm}$ needle were used for the injection. The needle was introduced under arthroscopic guidance in the suprasupinatus' tendon. Once the needle was well positioned, all the portals were sutured except the one for the arthroscope and the irrigation of the arthroscopic pump was stopped to prevent any leaks and out-flow of the plasma. Several injections in different areas of the suprasupinatus' tendon were performed.

\section{Post-operative protocol}

The post-operative protocol was identical in both groups. An immediate post-operative phase in order to restore passive mobility with cryotherapy to control pain and swelling, a passive, activeassistive and/or active ROM to tolerance (pendulum, pulley and/or wand exercises in all planes of motion) and submaximal isometric strengthening exercises as tolerated. A second phase with joint mobilization and stretching exercises, tubing exercises, particularly for internal and external rotation with the arm at the side, flexion and abduction strengthening should be kept to less than 90 degree and peri-scapular stabilization exercises as tolerated. Full return to work was allowed after 4 weeks and to sport 2 month.

\section{Patient follow-up and assessment}

Each patient was evaluated at a preoperative clinical evaluation and at the last follow-up mean of 39 month. Final assessment was by using a Visual Analog score for pain (VAS) [11], Constant score [12] and the quick DASH score [13]. The Constant is a subjective and objective score who was calculated following a detailed physical examination in a standardized fashion. The quick DASH and VAS are subjective scores and were completed by the patients. Return to sports activities and return to work were evaluated.

In addition to these measures, all local or general complications during the operative or follow-up phases were recorded. The same single operator performed all clinical follow-ups. A VAS $<5$ points

Table 1: Epidemiological and intraoperative data for the PRP and control group. Values are expressed as mean $+/$ - standard deviation or number (\%).

\begin{tabular}{|l|l|l|l|}
\hline & PRP group & $\begin{array}{l}\text { Control } \\
\text { group }\end{array}$ & p \\
\hline & $\begin{array}{l}\text { Epidemiological } \\
\text { factors }\end{array}$ & & \\
\hline Male & $18 / 24(75,0 \%)$ & $19 / 29(65,5 \%)$ & 0,45 \\
\hline Age & $52,63(+/-9,7)$ & $\begin{array}{l}58,10(+/- \\
13,9)\end{array}$ & 0,11 \\
\hline Dominance (right) & $21 / 24(87,5 \%)$ & $27 / 29(93,1 \%)$ & 0,49 \\
\hline Preoperative sport activities & $15 / 24(62,5 \%)$ & $3 / 28(46,4 \%)$ & 0,25 \\
\hline Preoperative professional & $9 / 23(39,1 \%)$ & $7 / 28(25,0 \%)$ & 0,28 \\
\hline activities & $\begin{array}{l}\text { Intraoperative } \\
\text { features }\end{array}$ & $2 / 28(7,1 \%)$ & 0,15 \\
\hline Biceps tendinopathie & $5 / 24(20,8 \%)$ & $9 / 28(32,2 \%)$ & 0,69 \\
\hline Superficial RC tears & $9 / 24(37,5 \%)$ & $5 / 29(51,7 \%)$ & 0,27 \\
\hline Superficial RC tears & $16 / 24(66,7 \%)$ & &
\end{tabular}

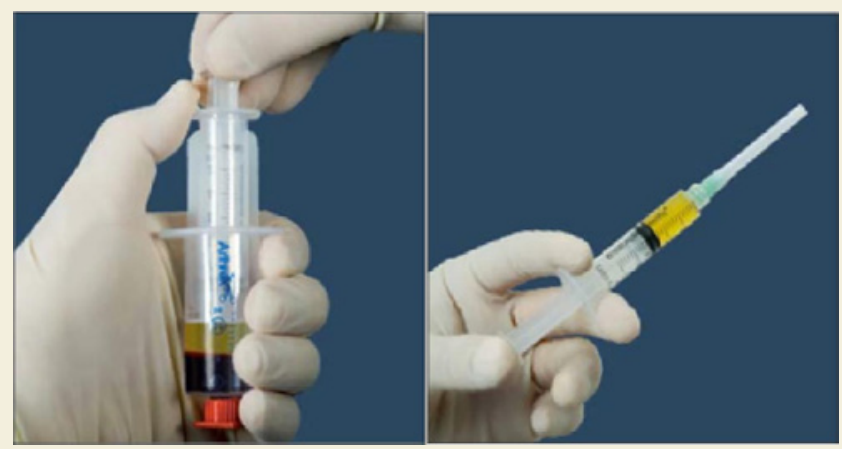

Figure 1: ARTHREX system for the collection of PRP with recovery of the supernatant thanks to the double sterile syringe. 
Citation: David Z, Thibault B, Lior A, Julien S. Efficacy of Platelet-Rich Plasma for Arthroscopic Treatment of Chronic Shoulder Impingement Syndrome: A Retrospective Study with a Minimum of 3 Years of Follow-Up. J Orthopedics Rheumatol. 2016; 3(2): 5.

ISSN: 2334-2846

and/or necessity to start again a medical treatment after surgery was consider as fail surgery.

\section{Statistical analysis}

The data were analyzed by Stata 1.3 software (StataCorp LP, Texas, USA). We tested differences between the treatment and control group for continuous variables with a Student $t$ test and for categorical variables with a X2 test. Significance was set at $\mathrm{p}<0.05$.

\section{Results}

\section{Pain result}

Mean follow-up at the time of pain evaluation was 37,3 months $( \pm 9,1)$ for PRP group and 41,4 months $( \pm 10,2)$ for control group.

Two patients in the control group needed to start a medical treatment after surgery with one infiltration and corticosteroids. It was called algodystrphic syndrome but with no radiologic proof. It was considering like a fail of acromioplasty

There was a significant difference for the two group between pre and post operative for pain scale (Table 2). There was statistical difference of the last follow-up between the two groups for the pain evaluated by VAS. The mean VAS at last follow-up was $1,17( \pm 1,27)$ for PRP vs $2,5( \pm 1,69)$ for control group $(\mathrm{p}=0,002)$ (Table 3$)$. We found a reduction of $3( \pm 2,4)$ points on a 0 -10 VAS scale in PRP group.

\section{Functional results}

Even there was a significant difference for the two group between pre and post operative for functional score (Table 2). There was no

Table 2: Preoperative and postoperative VAS and functional scales for both groups. Values are expressed as mean $+/$ - standard deviation.

\begin{tabular}{|l|l|l|l|}
\hline & Preoperative & Postoperative & p \\
\hline VAS & $4,7(1,9)$ & $1,9(1,6)$ & 0,00 \\
\hline Quick DASH scale & $58,9(17,8)$ & $24,2(17,7)$ & 0,00 \\
\hline Constant scale & $39,8(13,4)$ & $76,1(16,6)$ & 0,00 \\
\hline
\end{tabular}

Table 3: Clinical outcomes in the PRP and control group before surgery and at last follow-up post-op. Plus-minus values are means +/- SD. A value of $p<.05$ was considered significant.

\begin{tabular}{|l|l|l|l|l|}
\hline & PRP group & & Control group & p \\
\hline & VAS & & & \\
\hline Preoperative & 4,16 & 5,21 & $(1,83)$ & 0,052 \\
\hline & $(1,95)$ & & & \\
\hline Last follow-up & 1,17 & 2,5 & $(1,69$ & 0,002 \\
\hline & $(1,27)$ & & & \\
\hline & Constant & & & 0,610 \\
\hline Preoperative & 38,79 & 40,68 & $(13,32)$ & \\
\hline & $(13,78)$ & & & 0,200 \\
\hline Last follow-up & 79,25 & 73,32 & $(16,96)$ & \\
\hline & $(15,88)$ & & & 0,980 \\
\hline & Quick DASH & & & \\
\hline Preoperative & 58,83 & 58,94 & $(17,91)$ & 0,480 \\
\hline & $(18,12)$ & & & \\
\hline Last follow-up & 22,32 & 25,87 & $(17,46)$ & \\
\hline & $(18,26)$ & & & \\
\hline
\end{tabular}

statistical difference at the last follow-up between the two groups. The mean preoperative Constant scores were $79,25( \pm 15,88)$ for PRP group vs $73,32( \pm 16,96)$ for control group $(\mathrm{p}=0,20)$. Mean quick DASH scores were $22,32( \pm 18,26)$ for PRP group vs $25,87( \pm 17,46)$ for control group $(\mathrm{p}=0,48)$ (Table 3$)$. Mean normalized Constant-Murley score increased from 38 points $( \pm 13,8)$ pre-operatively to 79 points $( \pm 15,8)$ post- operatively in PRP group and from 40 points $( \pm 13,3)$ to 73 points $( \pm 16,9)$ in control group. However, there was no statistical difference in mean post-operative Constant-Murley score between groups.

Even for the return to spot and to work activities there was no statistical difference at the last follow-up between the two groups.

\section{Complications}

In both groups no complication had been found.

\section{Discussion}

The SIS is a frequently report shoulder complaints [14]. Currently there is no review that solely concentrates on the effectiveness of interventions for SIS only. Autologous PRP is an attractive biologic strategy to augment tissue healing $[15,16]$. The aim of the study was to evaluate if PRP injection after a simple a acromioplasty bursectomy improved functional and decrease pain in SIS The present study establish a significant difference between the two groups for the VAS score at last follow-up $(\mathrm{p}<0,01)$. But this study did not establish any significant difference between the two groups for the functional scores.

In the literature, the Effectiveness of surgical treatment for the SIS is not well demonstrates. Haahr in prospective randomized study of 90 patients found no differences between arthroscopic subacromial decompression and a graded physiotherapy strengthening program on the mean change in Constant score at 3, 6, and 12 months. Furthermore, there were no significant differences between the 2 treatment groups for pain score at 12 months, or between the Constant score $(>80)$ at 12 months [17]. As well as this prospective study of 125 patients who reported no differences in median Neer score between surgery and an exercise program at 3- and 6-month follow-up. No differences in the median pain scores (pain on activity, pain at rest, and pain at night) were reported between surgery and nonoperative treatment. This results differ from our study with significant outcome for pain et function post operative for the two group of treatment [18]. For some author the acromioplasty is the only way to treat the impingement. Ellman in a retrospective study of 50 patients found good results for pain and function at 1 to 3 years follow-ups but with no significant results [19]. De Baere with a followup of 19 month found a significant improvement on Constant score on this retrospective study [20]. We found the same significant results with a greater follow-up in our study that confirms the efficiency of arthroscopic acromioplasty.

There is only study, analyzing effect of PRP in a SIS, it was a prospective open study with 1 year follow up evaluated by VAS pain score and functional shoulder tests assessing rotator cuff strength. Include Patients received one ultrasound-guided injection of 3.0 $\mathrm{mL}$ of $1 \%$ xylocaine followed by $3.5 \mathrm{~mL}$ of PRP at the lesion and surrounding tendon. A significant improvement of pain, function, 
Citation: David Z, Thibault B, Lior A, Julien S. Efficacy of Platelet-Rich Plasma for Arthroscopic Treatment of Chronic Shoulder Impingement Syndrome: A Retrospective Study with a Minimum of 3 Years of Follow-Up. J Orthopedics Rheumatol. 2016; 3(2): 5.

was find in participants with refractory RCT [21]. It's a quiet interesting study but like our. Indeed, the beneficial effect of APC injections in tendon surgical repair has been shown in several studies, and could have potential applications in many fields in orthopedic surgery (Reconstruction of anterior cruciate ligament [22], tendon surgery [23], treatment of joint injuries [24], tendinopathie or muscle tears). Chahal realized a meta-analyze with 5 prospective study with 2 randomized [25]. The first one is a prospective randomized level one study, comparing clinical outcomes when using or not PRP as a matrix. Small to moderate lesions were repaired with double row procedure, and Constant score and MRI were performed 20 months after surgery [26]. No difference was seen in any group regarding clinical result and imaging. Authors notified one failure of repair in PRP group vs. 4 in control group, but no statistically significant difference was seen. Randelli did compare two groups with or other with- out PRP injection during repair [27]. Clinical outcomes and MRI were performed at 24 months. At 3 months all scores are better in PRP group, but with time, no difference continues. Just like in the previous study, MRI demonstrated higher failure in control group, without clinical difference. The study of Barber a level 3 study, including two groups of 20 patients, found a benefit of PRP in clinical out- come [28]. MRI found also a higher re-tear rate in control group with a statistically significant difference. Jo study didn't find any statistically significant difference between two groups of patient operated of a cuff repair with or without PRP injection [29]. One more time it appears a lower re-tear occurrence in PRP group, without statistically significant difference. Bergeson analyzed the effect of RPR on challenging cuff repair, including patient exposed to rotator cuff repair failure (aged, fatty infiltration) [30]. One more time, independently of clinical outcomes, it appears that PRP statistically increases the healing rate. Those different studies are not directly comparable to our study but like those one we can conclude that PRP decrease pain level and in this study pain level decrease for a long time (3 years)

This study had several limitations. First of all, only a small number of patients were available for evaluation. The ideal dose of PRP to inject is as yet unknown, and no study makes it clear whether an activator is needed or not. The platelet concentration in the PRP varies greatly from person to person and is therefore expressed as a multiplication factor of the platelet concentration in native blood [31]. The ACP Arthrex double siring is not the most concentrated PRP, but it seems that there is an ideal platelet concentration above which there may be a deleterious effect of the PRP on tendon healing [32]. It appears also important to control the leukocyte concentration. Indeed, the leukocytes are involved in the catabolic signaling, and an excessive leukocyte concentration in the PRP could have a negative effect on tendon healing [33]. The ACP we used for this study has no leucocytes and does not require the adjunction of an activator.

\section{Conclusions}

It was the first single operator study that evaluated PRP effect for arthroscopic treatment of chronic shoulder impingement syndrome with a long follow-up and with clinical and functional criteria.

The results suggest that PRP optimize the pain relief of the subacromial decompression in SIS.
The findings of the present investigation support the assumption that PRP application can positively affect long- term results of patients SIS. Future investigations are needed to confirm and strengthen these results.

\section{References}

1. van der Windt DA, Koes BW, de Jong BA, Bouter LM (1995) Shoulder disorders in general practice: incidence, patient characteristics, and management. Ann Rheum Dis 54: 959-964.

2. Burbank KM, Stevenson JH, Czarnecki GR, Dorfman J (2008) Chronic shoulder pain: part I. Evaluation and diagnosis. Am Fam Physician 77: 453460.

3. Neer CS 2nd (2005) Anterior acromioplasty for the chronic impingement syndrome in the shoulder. 1972. J Bone Joint Surg Am 87: 1399.

4. Neer CS 2nd (1983) Impingement lesions. Clin Orthop Relat Res 70-77.

5. Frost $\mathrm{P}$, Andersen JH (1999) Shoulder impingement syndrome in relation to shoulder intensive work. Occup Environ Med 56: 494-498.

6. Bodin J, Ha C, Petit Le Manac'h A, Sérazin C, Descatha A, et al. (2012) Risk factors for incidence of rotator cuff syndrome in a large working population. Scand J Work Environ Health 38: 436-446.

7. de Mos M, van der Windt AE, Jahr H, van Schie HT, Weinans $H$, et al. (2008) Can platelet-rich plasma enhance tendon repair? A cell culture study. Am J Sports Med 36: 1171-1178.

8. Peerbooms JC, Sluimer J, Bruijn DJ, Gosens T (2010) Positive effect of an autologous platelet concentrate in lateral epicondylitis in a doubleblind randomized controlled trial: platelet-rich plasma versus corticosteroid injection with a 1-year follow-up. Am J Sports Med 38: 255-262.

9. de Vos RJ, van Veldhoven PL, Moen MH, Weir A, Tol JL, et al. (2010) Autologous growth factor injections in chronic tendinopathy: a systematic review. Br Med Bull 95: 63-77.

10. Asfaha S, Cenac N, Houle S, Altier C, Papez MD, et al. (2007) Proteaseactivated receptor-4: a novel mechanism of inflammatory pain modulation. $\mathrm{Br}$ J Pharmacol 150: 176-185.

11. Farrar JT, Young JP Jr, LaMoreaux L, Werth JL, Poole RM (2001) Clinical importance of changes in chronic pain intensity measured on an 11-point numerical pain rating scale. Pain 94: 149-158.

12. Constant CR, Murley AH (1987) A clinical method of functional assessment of the shoulder. Clin Orthop Relat Res 160-164.

13. Gummesson C, Atroshi I, Ekdahl C (2003) The disabilities of the arm, shoulder and hand (DASH) outcome questionnaire: Iongitudinal construct validity and measuring self-rated health change after surgery. BMC Musculoskelet Disord 4: 11.

14. Huisstede BM, Wijnhoven HA, Bierma-Zeinstra SM, Koes BW, Verhaar JA, et al. (2008) Prevalence and characteristics of complaints of the arm, neck, and/ or shoulder (CANS) in the open population. Clin J Pain 24: 253-259.

15. Foster TE, Puskas BL, Mandelbaum BR, Gerhardt MB, Rodeo SA, et al. (2009) Platelet-rich plasma: from basic science to clinical applications. Am J Sports Med 37: 2259-2272

16. Lopez-Vidriero E, Goulding KA, Simon DA, Sanchez M, Johnson DH, et al. (2010) The use of platelet-rich plasma in arthroscopy and sports medicine: optimizing the healing environment. Arthroscopy 26: 269-278.

17. Haahr JP, Østergaard S, Dalsgaard J, Norup K, Frost P, et al. (2005) Exercises versus arthroscopic decompression in patients with subacromial impingement: a randomised, controlled study in 90 cases with a one year follow up. Ann Rheum Dis 64: 760-764.

18. Brox JI, Gjengedal E, Uppheim G, Bøhmer AS, Brevik JI, et al. (1999) Arthroscopic surgery versus supervised exercises in patients with rotator cuff disease (stage II impingement syndrome): a prospective, randomized, controlled study in 125 patients with a 2 1/2-year follow-up. J Shoulder Elbow Surg 8: 102-111. 
Citation: David Z, Thibault B, Lior A, Julien S. Efficacy of Platelet-Rich Plasma for Arthroscopic Treatment of Chronic Shoulder Impingement Syndrome: A Retrospective Study with a Minimum of 3 Years of Follow-Up. J Orthopedics Rheumatol. 2016; 3(2): 5.

19. Ellman $H$ (1987) Arthroscopic subacromial decompression: analysis of oneto three-year results. Arthroscopy 3: 173-181.

20. De Baere T, Dubuc JE, Joris D, Delloye C (2004) Results of arthroscopic acromioplasty for chronic rotator cuff lesion. Acta Orthop Belg 70: 520-524.

21. Scarpone M, Rabago D, Snell E, Demeo P, Ruppert K, et al. (2013) Effectiveness of platelet-rich plasma injection for rotator cuff tendinopathy: a prospective open-label study. Glob Adv Health Med 2: 26-31.

22. Vadalà A, lorio R, De Carli A, Ferretti M, Paravani D, et al. (2013) Platelet-rich plasma: does it help reduce tunnel widening after $A C L$ reconstruction? Knee Surg Sports Traumatol Arthrosc 21: 824-829.

23. Sanchez M, Anitua E, Azofra J, Andía I, Padilla S, et al. (2007) Comparison of surgically repaired achilles tendon tears using platelet-rich fibrin matrices. Am J Sports Med 35: 245-251.

24. Gobbi A, Karnatzikos G, Mahajan V, Malchira S (2012) Platelet-rich plasma treatment in symptomatic patients with knee osteoarthritis: preliminary results in a group of active patients. Sports Health 4: 162-172.

25. Chahal J, Van Thiel GS, Mall N, Heard W, Bach BR, et al. (2012) The role of platelet-rich plasma in arthroscopic rotator cuff repair: a systematic review with quantitative synthesis. Arthroscopy 28: 1718-1727.

26. Castricini R, Longo UG, De Benedetto M, Panfoli N, Pirani P, et al. (2011) Platelet-rich plasma augmentation for arthroscopic rotator cuff repair: a randomized controlled trial. Am J Sports Med 39: 258-265.
27. Randelli P, Arrigoni P, Ragone V, Aliprandi A, Cabitza P (2011) Platelet rich plasma in arthroscopic rotator cuff repair: a prospective RCT study, 2-year follow-up. J Shoulder Elbow Surg 20: 518-528.

28. Barber FA, Burns JP, Deutsch A, Labbé MR, Litchfield RB (2012) A prospective, randomized evaluation of acellular human dermal matrix augmentation for arthroscopic rotator cuff repair. Arthroscopy 28: 8-15.

29. Jo CH, Kim JE, Yoon KS, Lee JH, Kang SB, et al. (2011) Does platelet-rich plasma accelerate recovery after rotator cuff repair? A prospective cohort study. Am J Sports Med 39: 2082-2090.

30. Bergeson AG, Tashjian RZ, Greis PE, Crim J, Stoddard GJ, et al. (2012) Effects of platelet-rich fibrin matrix on repair integrity of at-risk rotator cuff tears. Am J Sports Med 40: 286-293.

31. Mazzocca AD, McCarthy MB, Chowaniec DM, Cote MP, Romeo AA, et al. (2012) Platelet-rich plasma differs according to preparation method and human variability. J Bone Joint Surg Am 94: 308-316.

32. Boswell SG, Schnabel LV, Mohammed HO, Sundman EA, Minas T, et al. (2014) Increasing platelet concentrations in leukocyte-reduced platelet-rich plasma decrease collagen gene synthesis in tendons. Am J Sports Med 42: 42-49.

33. McCarrel TM, Minas T, Fortier LA (2012) Optimization of leukocyte concentration in platelet-rich plasma for the treatment of tendinopathy. $J$ Bone Joint Surg Am 94: e143. 